\title{
Current Trends in E-Learning and Future Scenario
}

\author{
B. Naresh ${ }^{1}$ \\ Dr. D. Bhanu Sree Reddy² \\ 1. Research Scholar, VIT Business School, VIT University, Vellore-14, India \\ 2. Senior Professor, General Management, VIT Business School, VIT University, Vellore-14, India
}

Doi:10.5901/mjss.2015.v6n5p484

\section{Abstract}

E-Learning is an emerging methodology of modern education. It is gradually growing very fast for last two decades in the education sector. All the university, schools and companies started offering online courses to satisfy the student needs, and to improve employee effectiveness. E-Learning can deliver more value at very less cost than any other traditional mode of education. This advantage is attached with high-operating leverage for e-Learning companies, should translate them into elevated margins and returns on capital in the industry. E-Learning provides more advantage and user friendly even though it has disadvantages. There are many issues that remain to be resolved including problems with assessment, plagiarism and high drop-out rates encountered at E-Learning. The findings released by the MIT-Harvard MOOCs collaboration are also known as edX with a University of Pennsylvania study that concluded only 4 percent of people who register for online course actually finished them. E-Learning provide classes as recorded lectures, E-Books, Blogs, Wikis etc. but it do not concentrate on the learner's perception. On considering these issues it is forward for research which is discussed as further. By the way the course will be getting more effective in psychological perceptive of learner and it will create an effective teaching and learning process. This study is based on the current trends of E-Learning and its future scenario towards the research process on educational technology. The scope of the e-learning has spread its root wide and depth in all educational institutions varies from schools to colleges and even in organisation for training and development for their employees.

Keywords: E-Learning, Educational Technology, Educational Psychology, E-Learning Management, E-Learner Satisfaction, Higher Education Policy.

\section{Introduction}

E-Learning is fast and easy way of teaching and learning through network technologies which gains most powerful response in the present education trend. It is used worldwide from k-12 schooling, education institutions and various sectors of corporate world. The current work forces expected to be highly knowledgeable and skilled. It also expects that the learning process should take place continuously and acquire new skills by engaging in lifelong learning. E-Learning takes place in two ways for which involvement of the candidate with self discipline and self-motivation at higher degree is required. Synchronous method allows more number of candidates to learn, to exchange ideas and views at the same time. Asynchronous is independent learning method. A recent study reveals that Asia is in leading growth rate of $17.3 \%$ which is followed by Eastern Europe -16.9\%, Africa - 15.2\%, and Latin America - 14.6\%,it is expected, by 2016 the revenue of E-Learning market may reach $\$ 51.5$ billion. From Morgan \& Keegan point of view, the amount spends on all modes of education go beyond $\$ 750$ billion in the USA and it exceeds $\$ 2$ trillion worldwide. When compared with other sectors in education industry, the revenue from E-Learning is surpassing. The venture capitalist estimated the US market capitalization of the listed companies involved in E learning as US \$50Billion, which will reach \$US200 in 3 years this is greater than the asset value of Australia's 36 to 37 universities added together. Kate Fry, (2001). Growth of e-learning not only depended on infrastructure but also on few intangible things like perception of students, teachers, etc. Current research focuses on reasons for drop-out ratio, one of the major challenges faced by e-learning industry. The challenges are perception and readiness of the students and teachers towards the e-learning and the solution to overcome it.

\section{Review of Literature}

The e-learning has undergone many changes and the growth and development is tremendous in the short duration of time. Technology enhancement has made the e-learning simpler and provides more choice to the users. This paper discuss of the perception of users and the evolution of e-learning indifferent stages. 


\subsection{Evolution of E-Learning}

\subsubsection{Multimedia Learning}

Multimedia learning as the name suggestsit's the learning offered with the combination of two or more media such as audio, video, images and music etc... So the traditional education materials are translated into interactive electronic form due to multimedia technology and authorized tool. It helps the teacher, student and whole education system to revamp their educational design process curriculum into interactive and rich media learning. It helps to make communication process strong and reinforcingand innovative methods of learning and teaching process. This methodology gains its popularity since it motivates the student and provides numerous ways to express the views and ideas. Due to the multimedia technology, the retention rates of the learners is about $75 \%$ which is greater than $40 \%$ rate from see and hear method and 20\% from they see only method. Tse-Kian Neo (Ken) Mai Neo, (2004), Bernard Scott Chunyu Cong, (2010).

\subsubsection{Technology-Enhanced Learning (TEL)}

The learning enriched with technology enhancement i.e. learning process aided with or delivered in any form of technology like internet, computers, video conferencing, etc. the technology enhanced learning benefits both the provider and the learner. In provider perspective it is efficient cost saving to performance and other strategic benefits. For learners it includes instant and personalized feedback, Reusable learning material and a lively environment.TechnologyEnhanced Learningsurpasses time, location and circumstances. It offers the student the option of time, place and bring out different learning style. It's a broad spectrum at one point of time it include course with simple electronic syllabus, while the opposite end is with a vigorous, multimedia rich, interactive, collaborative online course. The integration of technology and the type and amount of technology is based on the objectives and the content of the course and the teaching methodology. Carol Rainsford Eamonn Murphy, (2005).

\subsubsection{Computer-Based Instruction}

Rapid development of communication and information technology results in usage of computer for education. It provide comfortable environment for students for learning. Computer-Based Instruction helps to create interest and motivation among students. The development and usage of multimedia such as audio-visual materials, animation, etc resulted in development of computer based techniques. The teaching and learning activity that uses the computer is known as Computer-Based Instruction. It is an add-on complement to the class room education and it motivates students and provides an interesting and exciting study atmosphere.Much software was produced for Computer-Based Instruction to solve the troubles in course and to avoid pessimistic efforts of memory based learning system. It serves as teaching material and also helps student for creating tables, calculation, etc for whole subjects.Roger Miles, (1977).

\subsubsection{Computer Managed Instruction}

The use of technology with the help of computers to faculties and guide them the key feature of computer managed instructionused are testing, analysis and record keeping. It also instructs and judges the performance of each student at regular intervals of time. The computer managed instruction includes simulation, problem solving program, etc. the system is effective only if the tutor is proficient with the utilization of computer. (Fall Joint Computer Conference, 1970, Quality Educational Development, Inc., Washington, D.C)

\subsubsection{Computer-Based Training}

The Computer-Based Training is for tutors whereas Computer-Based Training is for both education and industry. since the level of programming skills required for working with high technology and involves high cost but with less or no market viability. It involves more analyst and technicians so it's very expensive process.Dennis James, (1987).

\subsubsection{Computer-Assisted Instruction}

Computer-Based Training is done with help of analyst whereas Computer-Assisted Instruction is highly automated form of learning system. It includes simulation that adds realism and wide variety to learning. In this each student is provided with 
a computer terminal. It reduces the cost, danger and other factors that limit the scope for practical activities. It is mainly used for science which uses many illustration and demonstration. The key concept is that computer can adjust the instructional sequence according to the individual sequences according to the Progress and Needs of the student.Roger Miles, (1977)

\subsubsection{Web Based Learning}

The above mentioned types of learning are offline learning. Web Based Learning is online learning but when it was introduced, this technology is unknown to trainers.At later stage when compared to other modes, it helps to get the desired outcomes. The business people started to realize that it is easy and effective as well as less expensive way to train the employees. When conducted survey on WBT regarding its effectiveness most of the participants were from organization that implemented $78 \%$ of internetand the organizationwhich are intending to $69 \%$ of it.Tim Kilby, (2001).

\subsubsection{Virtual Learning Environment}

Virtual Learning Environment is a web based learning but it gives the class room atmosphere virtually i.e. it provides virtual access to class, exam and assessment etc... It is a component of current distance learning system. But it can be integrated in the physical learning and provide blended learning. The virtual learning is of two ways synchronous and asynchronous.

Synchronous is group of student gathered in a physical place and a teacher conduct class in virtual environment but they can communicate with each other.Asynchronous learning is independent learning but students are expected to complete the learning process, assignment etc... within the dead line. The students and teachers from different places can communicate and collaborate virtually with the help of virtual learning environment, they can present power points, raise questions and debate using tools available in application. Nicholas Joint, (2005).

\subsubsection{M-Learning}

Mobile learning is different from the traditional class room based learning. The learning can be take place at anywhere and anytime with the help of personal education devices like MP3, handheld computers. It replaces books and notes with these small devices. It provides the facilities like mobility to learners, time and location convenience. This method has proven increase in exam score, percentile and reduce the technical dropout rate by $22 \%$. It also plays vital role for storing the information and information management in Department of Defense (DOD) and Department of Homeland Security (DHS), etc.Yong Liu Shengnan Han Hongxiu Li, (2010).

\subsubsection{Massive Open Online Course MOOCs}

Massive Open Online Courses is one of the online learning models to connect and collaborate the way, on engaging the learning process. MOOCs are an open online course which built to share information and it is an event where, people talk about the topic and work together in a structured way. The work gets done in an accessible way, to read, reflect and comment on it. The course content is distributed in blog spot, discussion boards, video response, articles, tweets and tags where all together need to create a network.Significantly, MOOCs is build to engage the learners to self-organize theirparticipation with reference to their prior knowledge and skills and their interest and goals. It allows students to have global reach, develop knowledge and help to attain their learning goals by providing high quality course. Any number of students can take part in the subject they offer. Thomas Clarke, (2013)

\subsubsection{Selective Open Online Course SOOCs}

The selective open online courses are similar to massive open online courses but with different types namely private and selective. The private is for practical purpose similar to traditional online courses. The selective type is the innovative, i.e. anyone can apply but the enrolment is limited it is a next generation MOOCs. Even though, SOOCs numbers are less, but they are immense when compared to traditional on ground courses. The courses are free but its restricted to smaller number ranging around tens and hundreds. The selective criteria of SOOCs help to overcome the critical problem that overwhelmed MOOCs: one- low level of active participation, low retention rates \& variable student backgrounds and much more. The limited enrolments of SOOCs have become serious \& Effective online learning platform. The gap 
between the gap staff\& Student leads to issue in interaction and in shifts to peer to peer supports for guidance and feedback. The selection criteria help to overcome the above difficulties and pave the way for success. In SOOCs for first few weeks student accept and based on their performance level, they will be retained. In other words it's a two stages enrolment process that's initially open to all but became selective progressively at later. (Source:.http://etcjournal.com/ 2013/09/26/spocs-are-mooc-game-changers/).

\section{Objectives}

- To analyze the current trends in E-Learning and their future scenario towards the process of educational technology.

- To examine the technological transformation on E-Learning.

- To evaluate the learner perception on E-Learning technology (Educational Technology).

\section{Research Methodology}

According to Redman and Mory research is defined as "systematized effort to again new knowledge". Research methodology is a process used to collect information and data from the users for the purpose of business decision making. The methodology is for research publication, interview, survey, and other research techniques, and it includes the both present and historical information.

According to Burns and Grove (2003:195) define a research as "a blueprint for conducting the study with maximum control over factors that may interfere with the validity of the findings".

In this research, Non probability sampling method has been used based on purposive sampling. Where the researcher chooses the sample of their own choice based on who they think would be suitable for the study. We conducted a series of in-depth interview with among a mixture of students to examine the validity of our research model. The study participants are the graduate students, who have done at least one primarily online educational course. In this research, the data collection is based on the semi-structured one to one interview among the learners perception on online education. In person focus group interview among students place and major role in this research analyzes.

\section{Future of $E$ Learning}

The E-Learning comprises of many form of electronically supported learning and teaching with the help of information and communication system as a median. The $E$ Learning is entering into the world of exciting visuals; it is practical and cost effective for both learner and for educational institutes to delivery and manages administrative aspect of education at the same time. In additional if research work based on student perception and technology is done it will be very useful efforts should be taken to engage the student while undergoing E-Learning improve the effectiveness of teaching and learning process and to retain student. Self-evaluation should be done by the learners weather they can give full attention, selfregulation, and self-discipline to undergo $\mathrm{E}$ Learning. The institution can also keep this test to select the candidate to reduce the dropout rates.

\subsection{Sensitive Open Online Courses (SEOOCs)}

Sensitive open online course (SEOOCS) is similar to the massive open online course (MOOCS). As well as, in selective open online course the student will have a screening test to identify their attitude and perception towards the online learning and their expectation from the course. In current scenario the student can prefer their, required course and flexible timing, but due to the upgrading on latest technology, the online learning and teaching process is become more effective. The online course providers does not concentrate on the learners psychological perceptive like, cognitive perceptive and behavioral perceptive. Due to this, there is an increase in high dropout ratio and high failure rates in the online learning process. To avoid this ratio, the course providers should concentrate on the customer's perception and their attitude along with the right technology, so that the teaching and the learning process will become more effective. Otherwise the course provider can also adopt the customer's opinion on their course selection and technology. 

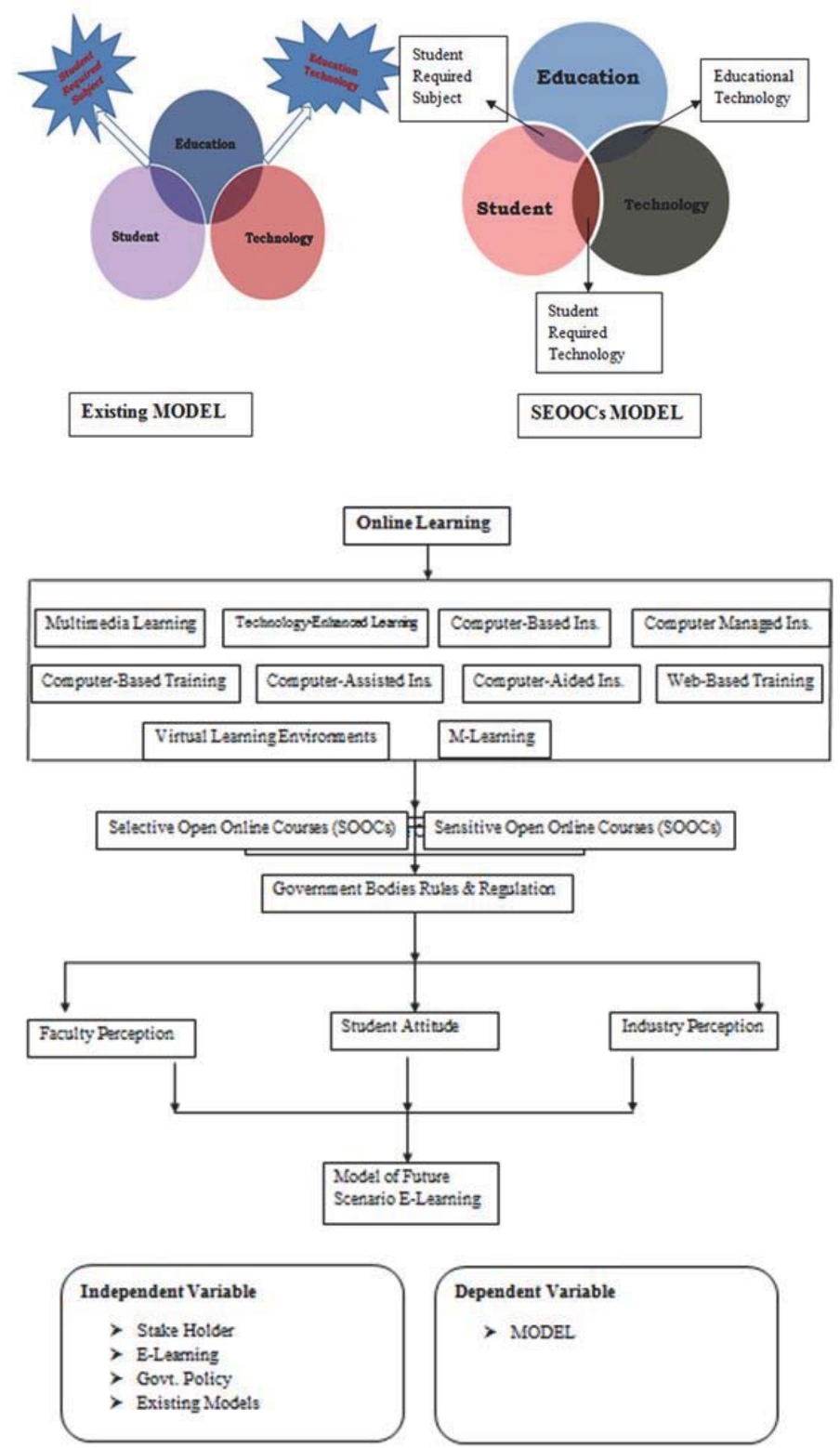

Figure 1: Conceptual Framework on Online Learning

\section{Limitation}

Large number of sample size has not been used in this study. This study is mainly concentrate on some specific students from only one university. So results may not generalize when comparing to other universities. In this study the overall validating adds to previous research that student's perception of support is directly related to their course satisfaction and outcomes on learning 


\section{Conclusion}

Online E-Learning is Vice versa for traditional learning (Face to Face). Many institutions and organization implement the e-learning process to train and develop the students and full time employees to improve their skills and productivity. Elearning environment is getting more completed due to various courses offered through internet. Initially the learners were satisfied with the e-learning process, but when it is implemented as a practical section the dropout ratio has been increased among the learners. The major problem is the online courses which do not concentrate on psychological factor of learner like Cognitive, Behavioral, Social, Developmental, Constructivist and the courses are studied by Different age group, culture, designated people and the expectation from the course is highly vary from one another. so while creating and delivery the course by analyzing the learner perception and the psychological perceptive by the way the course will be getting more effective in psychological perceptive of learner and it will create an effective learning and teaching process.

\section{References}

Andrew Ettinger Viki Holton Eddie Blass, (2006),"E-learner experiences: what is the future for e-learning?", Industrial and Commercial Training, Vol. 38 Iss 4 pp. $208-212$

Bernard Scott Chunyu Cong, (2010),"Evaluating course design principles for multimedia learning materials", Campus-Wide Information Systems, Vol. 27 Iss 5 pp. $280-292$

Carol Rainsford Eamonn Murphy, (2005),"Technology-enhanced learning", Journal of European Industrial Training, Vol. 29 Iss 6 pp. 457 $-471$

Dennis James,(1987),"Computer Based Training", Education +Training, Vol. 29 Iss 2 pp.11 - 12

Jacqueline S. VIERLING, M. SHIVARAM,(Fall Joint Computer Conference, 1970,) Quality Educational Development, Inc., Washington, D.C. in conjunction with the New York Institute of Technology and the United States Naval Academy under the United States Office of Education Contract No. 8-0446.

J.B. Arbaugh (2009)" Research in online and blended learning in the business disciplines: Key findings and possible future directions" Internet and Higher Education 12 (2009) 71-87

Kate Fry, (2001),"E-learning markets and providers: some issues and prospects", Education + Training, Vol. 43 Iss 4/5 pp. 233 - 239.

L. Barnard - (2009) "Measuring self-regulation in online and blended learning environments" Internet and Higher Education 12 (2009) 162008.

Nicholas Joint, (2005),"Strategic approaches to digital libraries and virtual learning environments (VLEs)", Library Review, Vol. 54 Iss 1 pp. $5-9$

Pei-Chen Sun, et al; (2006)"What drives a successful e-Learning? An empirical investigation of the critical factors influencing learner satisfaction" Computers \& Education 50 (2008) 1183-1202

Roger Miles, (1977),"Computer assisted learning", Industrial and Commercial Training, Vol. 9 Iss 12 pp. 513 - 518.

Sang Joon Lee, et al;(2011)" Examining the relationship among student perception of support, course satisfaction, and learning outcomes in online learning" Internet and Higher Education 14 (2011) 158-163

Tim Kilby, (2001),"The direction of Web-based training: a practitioner's view", The Learning Organization, Vol. 8 Iss 5 pp.194 - 199

Tse-Kian Neo (Ken) Mai Neo, (2004),"Classroom innovation: engaging students in interactive multimedia learning", Campus- Wide Information Systems, Vol. 21 Iss 3 pp. $118-124$

Thomas Clarke, (2013)"The advance of the MOOCs (massive open online courses) The impending globalization of business education?" Education \& Training Vol. 55 No. 4/5, 2013 pp. 403-413

Utku Köse ,(2010)"A blended learning model supported with Web 2.0 technologies" Procedia Social and Behavioral Sciences 2 (2010) 2794-2802

Woolfolk, A.E.; Winne, P.H. \& Perry, N.E. (2006). Educational Psychology (3rd Canadian ed.). Toronto, Canada: Pearson.

Yong Liu Shengnan Han Hongxiu Li, (2010),"Understanding the factors driving m-learning adoption: a literature review", Campus-Wide Information Systems, Vol. 27 Iss 4 pp. 210 - 226

\section{Weblink:}

http://etcjournal.com/2013/09/26/spocs-are-mooc-game-changers/

http://www.emarketer.com/

http://hechingerreport.org/ 